\title{
‘Nosotros éramos una cooperativa de distribución': Algunas transformaciones en el mercado de drogas ilegalizadas en un barrio popular de Rosario, del cuenta-propismo a una comercialización a mayor escala Eugenia Cozzi \\ Universidad Nacional de Rosario, Santa Fe, Argentina
}

'Nós éramos uma cooperativa de distribuição': Algumas transformações no mercado de drogas ilegalizadas em um bairro popular de Rosário, de trabalho autônomo a uma comercialização em larga escala analisa algumas transformações no mercado ilegal de drogas - maconha e cocaína ocorridas nas duas últimas décadas em um bairro popular da cidade de Rosário, na Argentina. A partir da reconstrução, em uma perspectiva etnográfica, da trajetória de jovens pertencentes a três diferentes gerações, pretende-se dar conta de mudanças mais gerais. As transformações serão apresentadas e organizadas em três dimensões: as formas de organização e distribuição interna de tarefas e a configuração de posições e papéis variados nesse mercado, a forma de venda de drogas ilícitas no varejo e, finalmente, as formas de se relacionar com a polícia. Palavras-chave: mercado, drogas, crime, juventude, polícia
'We Were a Distribution Cooperative': A Few Transformations in the Banned Drugs Market in a Neighborhood in the City of Rosario, from SelfEmployment to Commercialization on a Large Scale analyzes some transformations in the market of banned drugs - marijuana and cocaine - that occurred in the last two decades in an urbanpopular neighborhood in the city of Rosario, Argentina. Based on the reconstruction, from an ethnographic perspective, of the path followed by young people belonging to three generations, it is intended to account for more general changes. The transformations will be presented and organized in three dimensions: the forms of organization and internal distribution of tasks and the configuration of varied positions and roles; the form of retail sale; and finally, the ways of linking with the police.

Keywords: market, drugs, crime, youth, police

\section{Introducción}

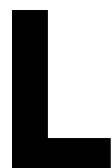

a ciudad de Rosario con un millón habitantes ${ }^{1}$ es la tercera más importante de Argentina, ubicada a la vera del río Paraná, con una dinámica productiva con acento en resortes financieros y de servicios en general (GAÑÁN, 2017), con un más que significativo movimiento portuario ${ }^{2}$, ha sido etiquetada en más de una oportunidad como la Chicago Argentina. La referencia a esta ciudad de ese modo reposa en varias historias. En sus orígenes dicha analogía, utilizada especialmente por periodistas, estuvo vinculada al desarrollo económico de la ciudad; luego, a principios del siglo XX, se ligó más bien a cierta criminalidad, caracterizada como "la mafia rosarina" (AGUIRRE, 2010). Pareciera reeditarse, ahora comparándose con otras ciudades de la región, ligadas a otro tipo de criminalidad.

Es decir, en los últimos seis años aproximadamente, se fue consolidando una imagen de Rosario como ciudad narco, en parte, como resultado de lo que varios actores sociales 
(periodistas, funcionarios políticos, judiciales y policiales, organizaciones sociales o políticas, expertos, entre otros) caracterizaron como el epicentro del avance del narcotráfico en este país ${ }^{3}$. Así, especialmente a inicios del año 2012, el narcotráfico como problema comenzó a instalarse como uno de los temas centrales en las agendas (públicas y mediáticas) (GAÑ̂́N, 2017); y se constituyó en una categoría que intentaba ser auto-explicativa de una variedad de fenómenos, por ejemplo del marcado aumento los homicidios registrados en la ciudad ${ }^{4}$.

Sin embargo, cabe preguntarse si es posible relevar indicios de un particular desarrollo y expansión del mercado de drogas ilegalizadas ${ }^{5}$ en Rosario, en los últimos años. En este sentido, durante esos años, en el trabajo de campo en un barrio popular de zona sur de la ciudad, las actividades ligadas al mercado especialmente de marihuana y cocaína - producción, tráfico y comercialización al por menor o menudeo, en el ámbito interno - aparecieron de manera subrayada en la mayoría de los relatos. Es decir, tanto adultos como jóvenes del barrio remarcaron en más de una oportunidad, cómo en las últimas dos décadas, por diversos motivos, estas actividades ligadas a la venta y consumo de marihuana y cocaína eran cada vez más frecuentes y extendidas.

Ahora bien, las condiciones de posibilidad de las actividades e intercambios vinculados a ese mercado están, de alguna manera, ligados a procesos políticos y económicos macro-estructurales que tienen efectos en la configuración de las biografías de quienes participan. Es decir, la participación en estas actividades está del algún modo signada por cambios tanto en la forma de producción y comercialización de ese mercado, especialmente de la cocaína, en un particular contexto de recuperación económica y ampliación del consumo interno, (BERGMAN, 2016; KESSLER, 2013, 2014), como también de la moralidad asociada a esas novedosas formas de producción y comercialización (COZZI, 2018).

No obstante, intentar aproximarse a esas transformaciones más generales y estructurales conlleva serios obstáculos y problemas. En este sentido, una de las dificultades, sumada y ligada en parte al carácter ilegal de la mayoría de las actividades e intercambios vinculados a este mercado, se relaciona con la escasa calidad y cantidad de estudios académicos sobre el tema, a pesar de la proliferación de publicaciones sobre narcotráfico; por lo que, en consecuencia, sólo se pueden señalar trazos gruesos o tendencias de las diversas aristas que lo componen. Se insiste, tal como señalan varios autores, la información disponible suele ser no sólo escasa, sino también fragmentaria, poco sustentable y, muchas veces, contradictoria (BERGMAN, 2016; CORBELLE, 2010; RANGUGNI, 2006; TOUZÉ, 2008).

Sin embargo, a pesar de la baja calidad y escasez de la información disponible y del reducido número de estudios sobre la temática; en términos generales y con matices, y en lo que interesa a este trabajo, la mayoría de los autores señalan que en las últimas décadas, en algunas zonas de Argentina — entre ellas Rosario - , se produjo una cierta transformación y expansión en las actividades de 
producción, tráfico y comercialización; junto a una sostenida expansión, diversificación y masificación del consumo local de sustancias ilegalizadas (cocaína y marihuana, entre otras) (BERGMAN, 2016; CALABRESE, 2010; CORBELLE, 2010; EPELE, 2012; SAÍN, 2015; TOUZÉ, $2008)^{6}$ y de bienes y servicios en general, en un particular contexto de recuperación económica (BERGMAN, 2016; CORBELLE, 2010; RANGUGNI, 2006; TOUZÉ, 2008; TOKATLIAN, 2017).

En el contexto regional, Argentina desde hace años viene siendo caracterizada por los discursos oficiales y el saber experto cómo un país de tránsito, donde parte de la producción de cocaína proveniente principalmente de Bolivia, Colombia y Perú es introducida al país por vía terrestre, fluvial y aérea a través de las fronteras endeblemente controladas (SAÍN, 2015) y luego exportada especialmente a Europa (BERGMAN, 2016; CLAUS, GONZÁLEZ y SPEKULJAK, 2017) ${ }^{7}$. Sin embargo, de acuerdo a algunos estudios, en la última década se produjo un desplazamiento de la última fase de producción del clorhidrato de cocaína, con la instalación de cocinas $^{8}$ en las que se procesa o se estira la pasta base que comenzó a importarse, en ciertas zonas de algunas ciudades del país, incluso Rosario; y con la proliferación de laboratorios que producen precursores químicos; lo que habría generado una expansión y transformación del mercado local (SAÍN, 2015; RANGUGNI, 2006; TOUZÉ, 2008; BERGMAN, 2016).

La ciudad de Rosario por esos años experimentó una importante reactivación económica, vinculada especialmente a la agroindustria y el funcionamiento del puerto, con un evidente impacto en el sistema financiero, la industria de la construcción y el área de servicios. Tal como se mencionó, Rosario es la principal ciudad portuaria del país, sin una fuerte presencia de empleo público y con sectores financieros e inmobiliarios que absorben las ganancias provenientes de la actividad agroportuaria, convirtiéndola, en una ciudad fuertemente cuentapropista y muy activa económicamente, tanto para mercados legales como ilegales. De este modo, dicha recuperación económica acompañada del fortalecimiento del consumo interno vio florecer actividades ligadas tanto a la economía formal, como a la informal e ilegal, entre las que se incluyen la venta de drogas ilegalizadas.

Ahora bien, sin desconocer cómo inciden en la configuración de este mercado esos procesos políticos y económicos macro-estructurales, la clave en la que se trabaja en este artículo es otra. En este trabajo se describen y analizan algunas transformaciones producidas en el mercado local de cocaína y marihuana, en las últimas dos décadas, a partir de reconstruir experiencias de jóvenes pertenecientes a tres generaciones, vinculadas especialmente a la participación en dicho mercado, en un barrio popular de la ciudad de Rosario ${ }^{9}$. Se trata de experiencias de personas que fueron jóvenes durante la década del noventa, durante la del dos mil y quienes eran jóvenes al momento de la realización del trabajo de campo. 
Se propone, entonces, partir del análisis de experiencias de personas. En este sentido, interesa detenerse minuciosamente cómo esas transformaciones fueron leídas, interpretadas y percibidas y, cómo en función de eso, toman decisiones actores que están viviendo sus vidas en esas coyunturas, y desde la reconstrucción de esas experiencias poder dar cuenta también de algunas de esas transformaciones. En este sentido, resulta pertinente la recuperación que realiza Fonseca (2005) en el estudio de grupos populares contemporáneos de la perspectiva de la experiencia, que apunta a las implicaciones de vivencias particulares. Sostiene la autora que con esta perspectiva hallamos pistas que pueden llevarnos más allá del reduccionismo económico y del debate estéril entre esencialismo versus construccionismo. De este modo, "colocar la experiencia en el meollo de la teoría de cultura es una manera de introducir no solamente carne y hueso sino, también, conflicto movimiento y ambivalencia dentro del análisis" (FONSECA, 2005, p. 133) ${ }^{10}$.

Para reconstruir las experiencias de jóvenes, especialmente en las dos primeras generaciones muchos de los cuales han abandonado o se han alejado de estas actividades - recurro, entre otros materiales, a los relatos que sobre sus propias trayectorias realizan sus protagonistas. Es decir, gran parte de la reconstrucción de estas experiencias está centrada en la oralidad, en lo que sus protagonistas cuentan y desean contar, y la dimensión de aquello de lo que hacen no siempre es posible observarla - cuestión que implica una serie de mediaciones y recaudos ${ }^{11}$. La estrategia varía parcialmente al reconstruir las experiencias de quienes al momento de la realización del campo participan de dichas actividades, porque sus relatos pueden combinarse con observación participante en situaciones sociales diversas que permiten poner en tensión relatos, representaciones, acciones y prácticas.

Este trabajo de campo, de carácter especialmente etnográfico, con jóvenes que participan en actividades delictivas en barrios populares de la ciudad de Rosario se realizó entre los años 2008 al 2015, en un primer momento, en el marco de proyectos, programas y experiencias de gestión de políticas públicas en materia de seguridad ${ }^{12}$. En ese marco, entre los años 2008 y 2011, comencé a trabajar en La Retirada ${ }^{13}$, un barrio popular de la zona sur de la ciudad de Rosario. Conocí a algunos jóvenes de entre quince y veinticinco años de edad que participaban en ese momento en actividades delictivas, especialmente robos, en el mercado de drogas ilegalizadas (marihuana y cocaína) y en enfrentamientos físicos en los cuales se utilizan armas de fuego. No fue tarea sencilla vincularnos con estos jóvenes, para la cual nos dimos variadas estrategias. Así, en general el primer contacto intentábamos realizarlo en lugares públicos donde ellos habitualmente se encuentran, por intermedio de referentes barriales que los conocían y funcionaban como presentadores y/o traductores locales de nuestra propuesta. La presencia sostenida en el barrio durante esos años resultó un elemento clave para la construcción y consolidación de vínculos de confianza con estos jóvenes.

A partir del año 2011, ya en el marco de una beca doctoral, retomé una segunda etapa del trabajo de campo. Si bien continué realizando actividades de investigación, manteniendo el 
vínculo con varios grupos de jóvenes y referentes sociales, tuve que aclarar mi nueva pertenencia institucional y cómo habían cambiado los motivos por los que estaba en el barrio e incluso mi vínculo de trabajo. En este marco, entre los años 2012 y 2013 visité esporádicamente La Retirada y a algunos referentes y grupos de jóvenes que ya conocía. Esos encuentros eran casuales o combinados con algunos jóvenes con anterioridad, y nos quedábamos conversando, durante algunas horas, en los lugares que cotidianamente habitan (la esquina, el pasillo, la plaza, la cancha de fútbol) ${ }^{14} \mathrm{o}$ en los patios de sus viviendas. Finalmente, durante los años 2014 y 2015 las idas al barrio se hicieron más frecuentes, llegando en más de una oportunidad a más de una por semana.

En esta segunda etapa, contacté a personas entre treinta y cincuenta años de edad, que habían participado - algunas de ellas lo seguían haciendo - de robos y, también, en actividades vinculadas al mercado de drogas ilegalizadas. Hasta ese momento, en gran medida había conocido sólo a jóvenes de entre quince y veinticinco años de edad, aproximadamente, quienes estaban en esos momentos participando en esas actividades o comenzaban a hacerlo. Así conocí y conversé reiteradas veces con personas que al momento de realizar el trabajo de campo tenían aproximadamente treinta años de edad, que siendo más jóvenes habían participado de esas actividades, y a personas de cincuenta años de edad, que también en su momento habían participado en actividades ilegales. Algunos de ellos habían comenzado con actividades ilegales tradicionales como el robo y, con el paso del tiempo, habían abandonado esas actividades y se habían volcado a la venta de cocaína y marihuana.

Permanecer en el barrio durante casi seis años me permitió observar e interactuar en diversas situaciones (en un encuentro casual en la calle, en una visita a la cárcel o comisaría, en un cumpleaños, respondiendo ante un hecho de violencia policial o ayudando a resolver un problema, asistiendo al velatorio de algún joven muerto, entre otras), que no son obviamente todas las de la vida de los jóvenes pero que son significativas en cuanto a su variedad y diversidad. Mantener vínculos con los jóvenes de las tres generaciones durante todo ese tiempo, generó y habilitó un contexto de confianza, que me permitió conocer y comprender entre otras cuestiones sus experiencias y a partir de ahí reconstruir prácticas, representaciones y valoraciones ligadas a su participación en el mercado de drogas ilegalizadas y sus transformaciones a lo largo del tiempo.

Con fines heurísticos, dichas transformaciones serán presentadas y organizadas en el artículo en tres dimensiones. Por un lado, transformaciones en la forma de organización y distribución del trabajo en relación a tramos de las actividades vinculadas a la producción, tráfico y venta, y la configuración de variados puestos y roles. En segundo lugar, modificaciones en la forma de venta al por menor o menudeo. Y, finalmente, las variadas formas de vincularse con la policía, ya que no se puede comprender la configuración particular y específica de ciertos mercados ilegales, entre ellos el de drogas ilegalizadas, sin tener en cuenta la "interacción decisiva" (HIRATA, 2014) entre personas que participan en estas actividades y las policías. 


\section{El Gringo Arrieta y el cuenta-propismo}

En el año 2014 conocí al Gringo Arrieta, tenía alrededor de cincuenta años de edad y estaba terminando de cumplir una condena de trece años de prisión por delitos vinculados a la comercialización de estupefacientes. Hijo de un obrero ${ }^{15}$ y de una ama de casa, vivía en La Retirada hacía más de treinta años. En el año 1991, el Gringo salió con libertad condicional luego de estar seis años preso en la cárcel de Coronda, localidad cercana a Rosario, en la provincia de Santa Fe. "Hasta ahí eran todas causas de robos" (Gringo Arrieta). Hasta ese momento intercalaba entre el choreo (realizar robos) y el trabajo legal (informal) ${ }^{16}$. Estando en libertad realizó una serie de robos más y para el año 1994 dejó de robar y comenzó a vender cocaína. "Me dediqué a vender, movía ¿viste?” (Gringo Arrieta). Encontró otro (novedoso) rebusque para sobrevivir.

El Gringo no fue el único. A mediados y fines de los años noventa y principio de los años 2000, algunos ladrones comenzaron a vender marihuana y cocaína en la ciudad de Rosario, que traían de Paraguay y Bolivia.

Tattú, otro joven del barrio, de unos treinta años de edad, quien años atrás había participado en algunos robos recordó que, en La Retirada, algunas personas habían empezado a vender drogas a mediados de los años noventa.

- Antes la teníamos que ir a comprar afuera del barrio, fue un cambio grande cuando empezó a venderse droga acá, en una cuadra en frente de la comisaría toda una familia empezó a vender, la peatonal del porro [cigarrillo de marihuana] le decíamos, yo tenía doce o trece años y ya podía ir a comprar. Se hizo mucho más visible la venta de drogas, se vendía marihuana y pastillas, cocaína muy poco al principio, la cocaína no se vendía tanto en esa época, eran puntos muy específicos, era algo más caro, no se movía tanto. Me acuerdo que empezaron a venderse en papelito, en papel glasé, papelitos que valían cinco pesos, después sí empezaron más con la cocaína, después yo empecé a consumir. (Tattú)

Algunos ladrones aprendieron un clásico sistema inaugurado por contrabandistas paraguayos: una "cooperativa" que traía marihuana y hacía la diferencia al revenderla en el sur de Rosario. Viajaban, compraban y revendían. Cuando El Gringo salió de estar preso un amigo ladrón, había empezado a vender cocaína y lo contactó con este novedoso rubro (área o tramo de actividad económica) ${ }^{17}$. Tal como relató El Gringo, parte de su tarea, en un primer momento, consistía en fraccionar y estirar esa sustancia para agregarle valor y obtener mayor ganancia al revenderla al por menor o al menudeo; es decir, a consumidores finales:

— Le digo: “Qué estás haciendo?". Él me contesta: "Estoy vendiendo". Le digo: “¿Cómo es?". Me contesta: "Yo te doy cinco gramos, vos preparalo en bolsitas con papelito glasé". Me daba cinco gramos yo venía picaba todo, hacía un polvito, después hacía la medida y sacábamos diez papelitos de esos y yo los vendía diez pesos cada uno, ganaba cincuenta pesos. Así era mitad para él, mitad para mí. Él traía de Bolivia, la 
iba a buscar él a Tartagal. Llegaba ahí pasaba para el otro lado [cruzaba la frontera], ¿viste que ahí está todo el maneje?, y traía. En un principio, yo sólo era revendedor y después me hice sólo, porque yo era muy andariego, un busca. Si sos boliviano yo me arrimaba al lado tuyo y te decía: "Hola, ¿cómo va?, de dónde sos". Me contestaban: “De Bolivia”. Les preguntaba: ¿Qué haces acá?'”, qué sé yo. Me decían: "Vine a buscar trabajo", por ejemplo. Entonces, les ofrecía trabajo, les decía: "Vení yo te voy a dar". Le daba trabajo un par de días y después le iba sacando a ver de dónde era, y si conocía sobre esto, tema merca [cocaína] ¿me entendés? Cuando me decían que sí, les preguntaba: “Qué te parece si vamos a buscar, vamos compramos y después lo vendemos a medias?". Así te hago entrar, y una vez que entraste, listo. Después si querés seguís, sino abrite, pero yo ya tengo la línea [el contacto para vender]. (Gringo Arrieta)

El Gringo incursionaba así en el negocio narco junto a otros ladrones de zona sur de la ciudad, entre ellos Los Montero. Al principio, El Gringo vendía cocaína para otros. Luego en poco tiempo consiguió su propia línea y empezó contrabandear marihuana directamente, con un mayor margen de ganancia. Es decir, se convirtió él en un importador mayorista de marihuana que revendía a otros vendedores minoristas en la ciudad, ubicándose en una posición superior al interior de ese mercado. Se contactó con unos paraguayos y junto a otras cuatro personas conocidas de él - entre ellos El Viejo Abel Montero -, viajaron a Paraguay y trajeron marihuana para vender. Las redes de relaciones sociales, las redes de contactos, las lealtades permiten, facilitan y/o dificultan realizar determinadas actividades, intercambiar bienes materiales $y$ simbólicos (GARRIGA ZUCAL, 2010) y resultan así centrales en este mercado. Esas redes de relaciones, la confianza mutua, la experiencia compartida hicieron posible que el ladrón conocido de El Gringo le ofrezca vender cocaína cuando salió de estar preso; hicieron posible también que los paraguayos acuerden con él para ir a buscar mercadería para vender.

En relación a la forma de organización, El Gringo remarcó en más de una oportunidad que

- En mi caso no había banda, éramos cinco personas, yo era la cabeza, estaba mi hijo, Rodriguito, Cantino, que ahora está preso, y el finado Alexis. Con el resto, yo les vendía la mercadería y que ellos hagan como quieran, yo era el distribuidor mayorista. (Gringo Arrieta)

Una de las tardes en su casa les pregunté cómo era el sistema. Rosa, su esposa, manifestó al instante: "Nosotros teníamos una cooperativa de distribución" (Rosa). Todos, El Gringo, sus hijas e hijos, se rieron.

- Yo era un distribuidor mayorista, viajaba, cruzaba y me quedaba un par de días y volvía con la mercadería, en la frontera nadie revisa nada, pasas como si nada. Traía la marihuana y la repartía, cada uno hacia lo que quería después, le daba cien kilos a uno, cincuenta kilos a otro, cuarenta kilos al otro y así. Algunos vendían afuera, uno se iba para Córdoba, para Mar del Plata, para Entre Ríos, y acá en Rosario tenía gente también, pero acá en el barrio no. Eso cambió todo, ahora agarran un pibe [joven], le dan dos mangos [pequeña suma de dinero], antes no había búnker, se vendía en las mismas casas, esto es así vos tenés los cosos [haciendo referencia a los genitales masculinos] bien puestos cuando 
vendés, no cuando mandás, yo daba yo la cara, no tenía miedo de dar la cara, contra todo, con la policía, con la gente, con todo. (Gringo Arrieta)

Varios elementos de estos relatos, y el de El Gringo en particular, resultan relevantes para explicar la forma de vincularse con este novedoso rubro en este primer momento. A los fines de este trabajo nos interesa mencionar sólo algunos. En primer lugar, lo que parece haber en este grupo es una cierta división del trabajo, pero que no es igualitaria. Es decir, existe cierto reconocimiento de autoridad, mando y/o liderazgo, de uno por sobre los demás. Autoridad, mando y/o liderazgo ligada a una mayor experiencia en el rubro. El Gringo es quien abrió el negocio, quien tiene los contactos, quien sabe cómo manejarse. Estas cuestiones lo ubican en una posición de poder al interior del grupo, se le reconoce autoridad, mando y liderazgo.

Otra de las cuestiones que resulta relevante está referida a cómo se hacía el intercambio. En este sentido, El Gringo detalló que ellos vendían directamente al comprador, sin intermediarios y que las ventas se hacían en las propias casas. Esta forma de hacer las cosas resultó valorada como una muestra de valentía y coraje. Es decir, se valoraba positivamente que al venderse de manera directa se ponía la cara frente a los compradores y frente a la policía, y no se mandaba a otros a hacerlo, cuestiones que permiten demostrar de alguna manera que se trata de "hombres de bien", que tienen palabra y no tienen miedo, que se hacen cargo de sus acciones. Remarcó:

- Esto es así, vos tenés los cosos [haciendo referencia a los genitales masculinos] bien puestos cuando vendes vos, no cuando mandas, yo daba yo la cara, no tenía miedo de dar la cara, contra todo, con la policía, con la gente, con todo ${ }^{18}$. (Gringo Arrieta)

Al mismo tiempo que permite resaltar su valentía y coraje, al mencionar que daba la cara, se esforzaba en distanciarse de otras formas de vincularse al mercado de drogas ilegalizadas en el barrio que se van a consolidar con posterioridad. En este sentido, esta forma de intercambio cara a cara, de manera directa con la persona que vendía sufrió transformaciones tiempo después.

\section{Los Monteros y una organización a mayor escala}

Los Montero habitaban en el barrio lindero El Obús, oriundos de la ciudad de Goya de la provincia de Corrientes. Sus integrantes más conocidos son El Viejo Abel y Roxi, los dos hijos de ambos, El Flaco y Héctor y El Tobi, un hijo "de crianza”. Para los años noventa, El Gringo Arrieta y El Viejo Abel eran compañeros y solían robar juntos. Habían realizado algunos robos grandes. "Habían robado un banco en Santa Fe y se movían juntos con personas del ambientede otros lados, con gente de Buenos Aires" (Tattú). Tiempo después El Viejo Abel, junto a su mujer Roxi y sus hijos, al igual que El Gringo Arrieta, cambiaron 
de rubro y a empezaron a vender primero marihuana y después cocaína, a fines de los años noventa. Pero a diferencia de Los Arrieta, lograron consolidarse en el negocio, al menos por más de una década.

Esta expansión de Los Montero se dió en un contexto de transformación más general del mercado de drogas ilegalizadas, especialmente de cocaína, de recuperación económica y de ampliación del consumo de bienes y servicios en general (KESSLER, 2013). Tal como se mencionó, algunos autores indican que en la última década se produjo un desplazamiento de la última fase de la producción del clorhidrato de cocaína.

En gran medida estas modificaciones en la forma de producción de la cocaína, a principio y mediados de los años 2000, se han atribuido a políticas prohibicionistas implementadas en la década anterior, por la Secretaría de Programación para la Prevención de la Drogadicción y la Lucha Contra el Narcotráfico (Sedronar), en la órbita del estado nacional. Tales políticas prohibicionistas estuvieron centradas en un control efectivo de la exportación de precursores químicos necesarios para el procesamiento de la pasta base de cocaína, que hasta ese momento se exportaban en importantes cantidades a Bolivia y Perú, (RANGUGNI, 2006). Las medidas de control más o menos efectivas en los años noventa se supone generaron la sustitución de la entrada de cocaína elaborada, por el de pasta base, y como consecuencia, el traspaso de la última fase de producción a varias ciudades de nuestro país, entre ellas Rosario. Señala Rangugni (2006) que se produjo así una re-territorialización del circuito local cultivo-producción-exportación de la cocaína.

Durante los años 2005 y 2006 se habrían instalado las primeras cocinas de cocaína en algunas áreas de la ciudad de Rosario, hecho que se supone generó una expansión y transformación en el mercado local. Los Montero fueron mencionados como pioneros en la instalación de cocinas de cocción y estiramiento de pasta base en La Retirada y El Obús. En este sentido, Hugo, quien vive en La Retirada y es padre de dos jóvenes que participan de estas actividades, señaló algunos cambios en el novedoso rubro con la llegada de Los Montero. De acuerdo a su relato, hacía aproximadamente diez años atrás, "La bolsita de merca [cocaína] salía diez pesos y era de la buena [en relación a la calidad]" (Hugo). Recordó que tiempo después "La empezaron a cocinar acá y cambió muchísimo la calidad, ahora es puro químico" (Hugo). Relacionó ese cambio en La Retirada con la aparición del Viejo Abel en el rubro narco y señaló: "Ellos [Los Montero] fueron quienes empezaron a cocinar acá y por eso bajó la calidad, lo que ya no la traen de afuera" (Hugo).

De este modo, tal como relataron algunos jóvenes y demás habitantes de La Retirada, Los Montero habían comenzado vendiendo marihuana y cocaína en el barrio, pero con el transcurso del tiempo lograron comenzar a expandir su negocio y a hacerse más poderosos. Ese mayor poder apareció relacionado entre otras cuestiones a los arreglos que hacían con la policía, como se desarrolla en el último apartado. Pero, además, se dio en un contexto donde este mercado ilegal estaba transformándose. Es decir, se pasó a un sistema de comercialización a mayor escala y, en consecuencia, 
se comenzó a complejizar la división del trabajo en su interior, emergiendo así nuevas categorías y jerarquías en relación a los distintos segmentos de la actividad. En su mayoría los intercambios dejaron de ser cara a cara, para ser a través de empleados - algunos se encargan de la venta al por menor, otros de la protección del punto de venta -, que no participan de la ganancia del negocio, sino que su posición es subordinada y muy mal paga. Por otra parte, los intercambios dejaron de ser en kioscosen las propias casas y se comenzaron a instalar puntos de venta fijos denominados búnker ${ }^{19}$.

\section{De los 'kioscos' a los 'búnker': transformaciones en las formas de venta}

Como mencionamos, algunas de esas transformaciones estuvieron ligadas a las formas de vincularse y participar de este mercado, en un momento de plena expansión del rubro. De algún modo se pasó de una organización comercial más bien artesanal a una de mayor escala que impactó, por un lado, en la forma de venta; es decir, de venderse en kiosquitos en las casas de las personas encargadas de la venta a comenzar a instalarse puntos fijos de venta de drogas, denominados búnkeres y la venta a través de empleados, mencionados como soldaditos. Metodología que parece consolidarse en distintas partes de la ciudad con posterioridad.

En las conversaciones con Tattú, él también mencionó estas transformaciones:

- Las cosas fueron cambiando, antes cuando vos le ibas a comprar al Gringo, el que te vendía era El Gringo. Cuando le ibas a comprar a Los Montero, la que te vendía era La Roxi y así. Después, te empezaron a vender los pibes [jóvenes]. (Tattú)

- Los Montero son los primeros que empiezan a abrir búnkeres, normalmente no era así. lba a comprar yo o compraba ella [señala a su pareja] y le comprábamos a La Roxi, vendía a cinco pesos. (Tattú)

— ¿bas hasta al Obús? (Eugenia)

— Sí, hasta El Obús me iba a comprar. (Tattú)

- ¿En una casa? (Eugenia)

- En la casa de ellos vendían, vos ibas a la casa, te hacían pasar y te vendían ahí. Y no era eso de los búnkeres, eso hace poquito. (Tattú)

- ¿Cuándo empezó? (Eugenia)

- No sé, hace dos años debe ser. (Tattú)

- ¿Acá en La Retirada hay búnker? (Eugenia)

- No, no hay, en La Retirada no hay movimiento de venta. Es medio raro, porque hubo algunos traficantes pero no duraron mucho. Los que más movían eran Los Gaticas, que ahora no venden ellos. Ellos están ahora metidos en el negocio del Abel, manejan un poco los búnkeres de afuera, administran, van y cobran, cuentan la plata, ya no se queman vendiendo. Hay intermedios de ellos, intermediarios que son los soldaditos, que más o menos manejan. (Tattú)

— ¿Qué es soldadito? (Eugenia)

- Soldado es el que no corta ni pincha [sin poder], pero le dan la droga y lo tienen para el mandado, si tiene que hacer una cosa, si le tiene que pegar [disparar] a alguien, así. (Tattú) 
En este sentido, Los Montero fueron quienes, en un contexto de expansión del rubro narco, produjeron una organización comercial a mayor escala que implicó una mayor y más compleja división del trabajo en su interior. Es decir, Los Montero no sólo pasaron a vender en otras zonas de la ciudad, sino que, además, dejaron de ser ellos quienes vendían de manera directa, abandonaron los intercambios cara a cara y comenzaron a emplear a jóvenes para la venta al por menor y para otras actividades vinculadas a este mercado, a cambio de dinero, cocaína, marihuana, armas de fuego y municiones y/o protección ${ }^{20}$. Tattú hizo referencia así a cierta delegación de las tareas de ventas al por menor: "Ya no se queman vendiendo" (Tattú). Algunos venden, otros pasan a cobrar, otros cuentan el dinero recaudado.

El tiempo de los 'soldaditos': nuevas jerarquías en este mercado

Por otro lado, y ligado al punto anterior, este modo de comercialización a mayor escala implicó una división del trabajo más compleja y sofisticada, generando diversos y novedosos puestos al interior de ese mercado, creando nuevas alternativas para los jóvenes del barrio, aunque subordinada y muy mal paga. Participación subordinada que no se distancia demasiado de las características de participación de los jóvenes en el mercado de trabajo legal formal e informal, tal como señalan una serie de estudios en la región. Es decir, el tipo de empleo al que acceden en general son los más precarios, de menos ingresos y en donde abundan las relaciones informales (BENASSI, 2017; KESSLER, 2013). Asimismo, estas nuevas alternativas se tradujeron y/o impactaron en nuevas jerarquías en el mundo del delito local: narcos, transeros, sicarios, soldaditos y bunqueros, y, al lado, las tradicionales en relación a los ladrones: ladrones de caño y rastreros ${ }^{21}$.

Imagen 1: Jerarquías ligadas al mercado de drogas ilegalizadas a nivel local

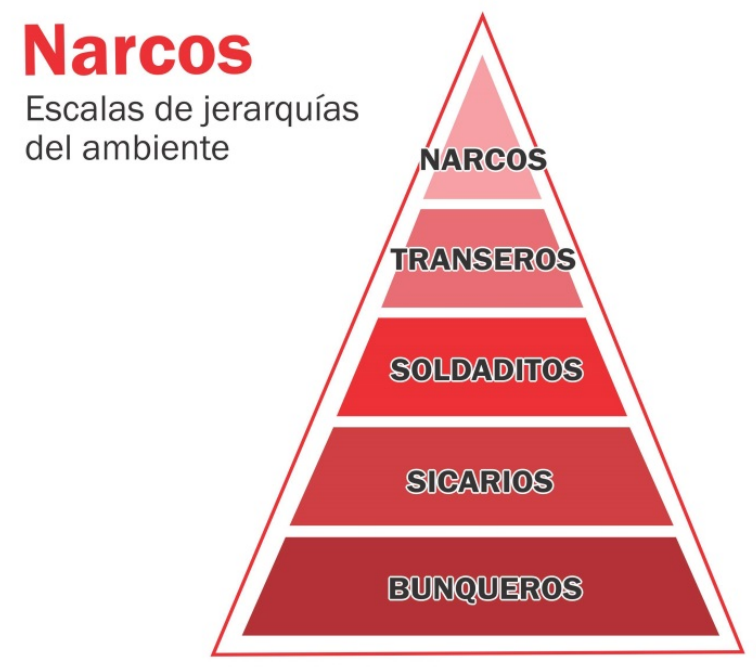

Fuente: Cozzi (2018). 
Las nuevas jerarquías ligadas a este mercado ubican a las personas en distintos niveles de poder, prestigio social y participación en la ganancia del negocio ${ }^{22}$. En sus extremos se colocan, por un lado, el narco, traficante o narcotraficante, se trata del dueño de negocio, en nuestro caso Los Montero, quien está en la cima de la estructura, participa del mayor margen de ganancia y da órdenes al resto y, por otro lado, en el extremo inferior, el soldadito ${ }^{23}$ - integrado también por sicarios y bunqueros - un mero empleado, "que no corta ni pincha" (Tattú). Asimismo, se incluyen toda una serie de escalas intermedias entre ambos polos. Esto es, en el medio están los transas o transeros, que están por debajo de los narcos y son los que se encargan de la venta al por menor.

- ¿Qué diferencia hay entre un transero y un narco? (Eugenia)

- El transero es el que te vende una bolsita [de cocaína], dos bolsitas [de cocaína]. El narco es el que viene con los pedazos y no distribuye solo acá, a todos lados, a Buenos Aires, Santa Fe, ahí está toda la mafia, están en otro lado [se refiere al Obús], acá [en La Retirada] no hay nada de eso. El narco es el que manda todo, después vienen sus allegados. Transero es el que vende, narco o narcotraficante son un par nomás, que consiguen traer de otros lados y venden a los que venden ${ }^{24}$. (Tattú)

A su vez, de acuerdo al relato de Caló, un joven de La Retirada, de unos treinta años de edad, preso y condenado por varios robos, entre los soldaditos también existen posiciones diferenciadas en relación a las actividades que realizan. Es decir, entre quienes venden al interior del búnker, denominados bunqueros, que son quienes se encuentran en el nivel más bajo de la jerarquía, los que cuidan el punto de venta (soldaditos), los que se encargan de amedrentar y/o herir a otros, mencionados a veces como sicarios, están por encima del resto de los soldaditos en la escala de prestigio y poder, por encontrarse en un lugar de menor subordinación y en mejores condiciones para demostrar coraje y valentía.

— En el rubro narco van por jerarquía, el que manda todo es el narcotraficante y después vienen todas las personas allegados a ellos. (Caló)

- ¿Después están los transas? (Eugenia)

- Están los transas, que son los que venden. Después están las personas que, no sé cómo llamarle, hay personas que se encargan ahora, es todo modalidad nueva ahora, ahora hay personas que se encargan. Yo tengo veinte búnkeres y a vos te dejo de encargado, que te encargues de que ese búnker esté bien, funcione bien. (Caló)

— De administrarlo. (Eugenia)

- Claro. Y llevarle vos, abastecerlo con la droga que le hace falta o si tiene que matar a alguien, lo tiene que matar. Podés estar vos, podés tener soldados vos. Le agarras y decís, les das la orden vos, "anda a matar a fulano" y van y lo matan. Si viene la orden de arriba, matar a tal persona, "anda y busquen a tal persona", lo amenazaron o algo. (Caló)

- ¿Es un soldadito eso? (Francisco)

- Los soldados hacen eso, sí. (Caló) 
— ¿El que se encarga del búnker también es soldado o no? (Francisco)

— También, son soldados pero son con más jerarquía, los que cuidan los búnkeres...(Caló)

— ¿Son los más bajos de todos? (Eugenia)

— No. Los más bajos de todos son los que están adentro. (Caló)

- ¿Los que están adentro? (Eugenia)

- Los que están adentro y los que están afuera también. Siguen segundo. Esos son los más... Diría lo más bajo que caen. (Caló)

— El encargado de ahí del búnker, que se encarga de administrarlo...(Francisco)

- Claro, a tal hora viene y le dice "vení que yo tengo las cien lucas [mil pesos] juntadas, pasa a buscarlas". Viene, le abre el candado de afuera y se lleva la plata. Ahora se modernizó todo. (Caló)

— ¿Antes cómo era? (Francisco)

- Antes no, antes se manejaban ellos mismos. (Caló)

- Ellos mismos vendían. (Eugenia)

- Vendían ellos mismos, los hijos y los mismos amigos de ellos también, que siempre están, eso cambió. (Caló)

En igual sentido relató Tattú:

- El soldado es el más perejil [menos poder y prestigio]. El sicario tiene que ir a matar, te pagan por una vida. El sicario es más que el transero y más que el soldado. El sicario te tiene que venir, se tiene que asegurar, te pega y te va y te remata, ese es el sicario. (Tattú)

De este modo, con los sicarios, lo que se delega es el uso de la violencia. Es decir, en algunas ocasiones ya no matan y/o amedrentan directamente sino que les piden a otros jóvenes que lo hagan por ellos, a cambio de diversos favores.

Estas posiciones o jerarquías, que indican diversas cuotas de poder, y eso hace al prestigio, no deben ser pensadas de manera rígida e inflexible. Es decir, una misma persona en distintos momentos o circunstancias puede realizar cual o tal actividad y ubicarse así en distintas posiciones jerárquicas. Son más bien posiciones o roles, que resultan cambiantes todo el tiempo, más que una construcción identitaria dentro de una estructura. Algunas de esas posiciones están totalmente desprestigiadas - de bunquero por ejemplo - y esto está relacionado a que los ubica en un lugar de mayor subordinación, menor poder y margen de ganancia y están en peores condiciones para demostrar valentía y coraje.

Recapitulando, en alguna medida, esta organización comercial a mayor escala vinculada a la producción, tráfico y venta, especialmente de cocaína, colaboró en la configuración de variados puestos y roles, relacionados a diversos eslabones de esa cadena, con diversa participación en las ganancias del negocio. Se establecían nuevas jerarquías, con distintos niveles de poder y prestigio. Sin embargo, esto no significa que los intercambios directos en las casas de las personas que vendían dejaron de suceder en los momentos posteriores, algunos jóvenes continúan vinculándose de este modo, es decir, cara a cara. Tampoco significa que las personas que integran 
la primera generación participaron siempre de manera directa en los intercambios ligados a este mercado. De hecho el propio Gringo comenzó vendiendo para otro. No obstante, en el primer caso, esos son los tipos de intercambio que prevalecen o dominan el mercado. En cambio, cuando la segunda $y$, especialmente, la tercera generación de jóvenes comenzaron a participar, mayormente lo realizaron bajo el nuevo esquema.

\section{‘Arreglar’ y 'trabajar': diversas formas de vinculación con la policía}

Finalmente, otra de las transformaciones identificadas estuvo ligada a las diversas formas de vincularse y/o negociar con la policía. Interesa detenerse en esta dimensión porque no se puede comprender la configuración particular y específica de ciertos mercados ilegales, entre ellos el de drogas ilegalizadas, sin tener en cuenta la "interacción decisiva" (HIRATA, 2014; HIRATA y GRILLO, 2017) entre personas que participan en estas actividades y las policías y/o fuerzas de seguridad, en tanto agentes directos y/o inmediatos del control y/o regulación gubernamental, a través de la cual se permite, regula y/o evita, de diversas maneras, la circulación de mercancías, (HIRATA, 2014; FELTRAN, 2011; HIRATA y GRILLO, 2017), resultando la misma legalidad objeto de intercambio (PITA, 2012; MISSE, 2007, 2017). Es decir, lo que se negocia - con diversos grados de limitada autonomía y/o libertad - es la aplicación o no de la ley, se produce así, una distribución diferencial de la legalidad y la violencia (PITA, 2012) ${ }^{25}$.

Los Arrieta sostuvieron una y otra vez que ellos, a diferencia de otros grupos ligados a ese mercado, cayeron [fueron detenidos] porque nunca quisieron arreglar con la policía. El Gringo resaltó en varias oportunidades:

- Nunca quise arreglar con la policía para vender, porque yo soy delincuente ${ }^{26}$, no tengo que arreglar con la policía. Por mi orgullo, yo arreglo con la policía y dejo de ser lo que soy: soy un vigilante, estoy trabajando con la policía. ¿Me entendés? (Gringo Arrieta)

Rosa agregó otra razón, resaltó: “Además, si trabajas con la policía mañana te querés abrir y no podes, fíjate lo que le pasa a los grandes jefes" (Rosa).

La censura de este tipo de arreglos, en el relato de algunos ladrones, aparece vinculada a dos órdenes de motivos. Por un lado, más vinculada a una censura moral, el honor del ladrón, del delincuente que no trabaja con la policía. "Si yo trabajo con la policía dejo de ser lo que soy" (Gringo Arrieta). Y, en un segundo lugar, los motivos que argumentaron estuvieron vinculados a una razón más práctica, de no querer depender de la policía, poder ser independiente y salir y entrar en el mercado ilegal cuando decidan. 
¿Qué significa entonces arreglar con la policía? ¿Qué arreglos están permitidos y cuáles te convierten en un vigilante y están, en consecuencia, prohibidos o mal vistos? Esta distinción resulta importante porque hace a formas de relacionarse y vincularse prohibidas, permitidas y habilitadas en este sistema de reglas. En este sentido, arreglar (intercambiar dinero, bienes o favores) con policías en el momento de la detención, para evitar ser o permanecer detenido, avances en la investigación penal o morigerar la situación procesal aparece permitida o, al menos, no censurada. En cambio, trabajar con la policía, esto es arreglar previamente, a través de un intercambio de bienes, servicios, dinero, favores, información, para que permitan, faciliten o dificulten el desarrollo de determinaba actividad, integrando de algún modo la organización, resulta fuertemente censurado. Sin embargo, este tipo de arreglos se producen.

Este tipo de acuerdo te convierte en un vigilante, un cagón [cobarde], un buchón [delator]. Pero, al mismo tiempo, te permite acceder a un tratamiento diferencial con la policía, a cierta protección, adquirir cierto status de protegido. Esto otorga mayor poder que el resto de los grupos: "Te hace intocable" (Tattú), al menos por un tiempo - cuestiones evidenciadas en la expansión de Los Montero. Es decir, no es un poder que los ubica por encima de otros de una vez y para siempre, sino que se puede perder, los acuerdos con la policía se pueden romper y con ello la protección de la que se gozaba. El intercambio con la policía aparece, entonces, en el marco de una relación más o menos asimétrica de poder ${ }^{27}$.

La categoría analítica "mercancía política" (MISSE, 2007, 2017) resulta útil para analizar estos intercambios entre policías y personas ligadas a este mercado. En primer lugar, porque el autor abstrae del análisis la dimensión moral para comprender esos procesos sociales $\mathrm{y}$, en consecuencia, le permite constatar "un continuum de variación sobre el mismo diapasón, aquel que va de la negociación moralmente ambigua hasta la más reprochable”, (MISSE, 2017, p. 42) ${ }^{28}$. Resulta productivo entonces analizar los diversos arreglos con la policía como intercambios aunque criminalizados, a veces permitidos, legitimados, tolerados; y otras veces fuertemente repudiados. Los Arrietas diferenciaban que no es lo mismo arreglar que trabajar con la policía.

En segundo lugar, porque el autor llama la atención que este tipo de intercambio se da necesariamente en el marco de una relación asimétrica de poder, en la cual se suelen negociar las condiciones del intercambio desde un lugar de subordinación. Es decir, la categoría de mercancía política abarca un conjunto de prácticas de intercambio que necesariamente involucra una relación asimétrica de poder. La policía se apropia del plus de poder ligado a la estatalidad que le confiere su función, la vende, la negocia para, por ejemplo ofrecer protección a determinados grupos permitiendo que desarrollen sus actividades sin mayores consecuencias y perseguir penalmente a otros, los que no trabajan con la policía. El cálculo económico queda, así, subordinado al cálculo de 
poder - aquí llamado cálculo político. Aun cuando el resultado del intercambio pueda ser, la mayoría de las veces, económico, sus condiciones de posibilidad son extra-económicas.

Misse (2007) destaca así el importante rol que han desempeñado grupos de policías, entre otros agentes del Estado, en la configuración de determinadas formas de organización de la criminalidad en Río de Janeiro. Advierte, entonces, la yuxtaposición de dos mercados ilegales uno que ofrece bienes económicos ilícitos - drogas, por ejemplo - y otro que lo parasita imponiendo el intercambio de mercancías políticas (MISSE, 2007). La policía participa de este modo en este mercado, integra de alguna manera las redes de relaciones que lo constituyen, teniendo un papel clave en la forma que se desenvuelven y desarrollan determinados mercados ilegales.

\section{Observaciones finales}

En este artículo se describieron y analizaron algunas transformaciones en el mercado de drogas ilegalizadas, producidas en las dos últimas décadas, en un barrio popular de la ciudad de Rosario, a partir de reconstruir algunas experiencias ligadas a ese mercado, de jóvenes pertenecientes a tres generaciones distintas. Las actividades ligadas a la producción, tráfico y comercialización al por menor o menudeo en el mercado interno de marihuana y cocaína aparecieron como prácticas cada vez más frecuentes y extendidas. Sin desconocer que las condiciones de posibilidad de esas actividades e intercambios están, de algún modo, ligadas a procesos políticos y económicos macroestructurales, la clave en la que se trabajó aquí fue otra, fue a partir del análisis de las experiencias de personas de carne y hueso. Me interesó detenerme minuciosamente en cómo esas transformaciones fueron leídas, interpretadas y percibidas y, cómo en función de eso, tomaron decisiones actores que estaban viviendo sus vidas en esas coyunturas, y desde la reconstrucción de esas experiencias poder dar cuenta también de algunas de esas transformaciones.

Así vimos cómo algunos ladrones cambiaron de rubro y empezaron a vincularse al mercado de drogas ilegalizadas a mediados de los años noventa, profundizándose este proceso en los años posteriores. La participación en estas actividades de los jóvenes de las dos generaciones siguientes estuvo signada por cambios tanto en las formas de producción y comercialización de ese mercado, como en la moralidad asociada a esas formas de producción y comercialización (COZZI, 2018).

La primera generación de ladrones que entró en contacto con este mercado, lo hizo en un momento en el cual éste no estaba tan desarrollado, como sí lo va estar para las generaciones posteriores. A su vez, participaron en ese novedoso rubro con la lógica del mundo de los ladrones, con la lógica del ladrón independiente sin patrón, de delincuente que no trabaja con la policía, que no se achica y se la banca e intentaron imprimir de esa lógica y de esos códigos su 
participación en las actividades ligadas a este mercado. La segunda generación participó en este mercado, cuando éste estaba en plena transformación, ligada en parte a la expansión y extensión del rubro narco inaugurado por la generación anterior.

De algún modo, se trató de una etapa de transición en la cual los narcos empezaron a ganar terreno que, al mismo tiempo, pareciera empezaron a perder los ladrones. Transformaciones que, además, van a estar consolidadas cuando los jóvenes de la tercera generación comiencen a participar, siendo ya parte del horizonte de posibilidades vitales. Es decir, se trata de actividades y/o intercambios posibles en relación también a cómo se han ido sedimentando experiencias entre las distintas generaciones, cierta experiencia histórica acumulada, o al decir de Fonseca (2005) cierta sedimentación de experiencia histórica. En este sentido, son posibles en gran medida porque existe un saber que los jóvenes ya tienen porque se han acumulado reservas de experiencias social y cultural posibles, en términos de Kessler (2013).

Finalmente, se identificaron diversas formas de vincularse con la policía. En este sentido, se producen diversos tipos de intercambios y/o negociaciones - en algunos casos, más o menos forzados - y arreglos entre policías y los jóvenes de las tres generaciones; a partir de los cuales, los policías persiguen, prohíben, permiten, toleran y/o promueven el comportamiento de personas o grupos y/o el desarrollo de diversas actividades, prácticas y/o intercambios ligados a este mercado. La policía, entonces, es parte integrante de esa densa trama de relaciones sociales y trafica un bien muy particular, las mercancías políticas (MISSE, 2007), teniendo así un rol clave en la forma como se desenvuelven y desarrollan determinadas actividades y/o prácticas, como también determinados mercados ilegales en este espacio social.

Cuestión que permite poner en discusión, además, algunas imágenes sociales que circulan sobre el mundo del delito, sobre el mercado de drogas ilegalizadas en particular y sobre algunos de sus protagonistas, producidas y reproducidas por diversos actores sociales. Es decir, en el contexto en el cual se desarrolló la investigación algunos barrios de la ciudad eran presentados como territorios ocupados y gobernados por grupos narcos en los cuales el Estado no podía ingresar y que estos grupos, de algún modo, le disputan poder al propio Estado. Si bien los grupos que trabajan con la policía cuentan con mayor de poder, ese poder es frágil ya que depende de mantener determinado acuerdo con la policía, siempre desde un lugar de asimetría. Es decir, la policía es otro actor que está jugando en este espacio social, que tiene un plus de poder dado por la propia estatalidad.

\section{Notas}

'Población de 1.240.000 personas, Censo Nacional de Población, Hogares y Viviendas 2010 (INDEC, 2012). 
${ }^{2}$ A grandes rasgos la actividad portuaria concentró la expansión económica de la ciudad, ligada al modelo de desarrollo agroexportador, desde finales de siglo XIX hasta los años treinta del siglo XX (ROBIN y DURAN, 2006; CRUCELLA y ROBIN, 2014). Con posterioridad, durante la etapa de sustitución de importaciones y del impulso del modelo desarrollista en el país entre 1940 y 1975, se instalaron en la región una serie de grandes industrias, provocando un importante crecimiento demográfico. Condiciones económicas favorables que, al igual que en el resto del país y la región, comenzaron a deteriorarse a mediados de los años setenta, profundizándose durante los años noventa, con aumento del desempleo y la pobreza. Es decir, para el año 2002, más del 50\% de la población de Rosario estaba por debajo de la línea de pobreza (BENASSI, 2017), situación que comenzó a revertirse a partir del año 2003. Durante esos años Argentina comenzó un ciclo de recuperación económica y social (KESSLER, 2013). En Rosario, la situación ocupacional mejoró notablemente, de la mano de la reactivación económica, del notable crecimiento del mercado interno, la consecuente redistribución de ingresos y la ampliación del consumo de bienes y servicios en general (RUBINZAL, 2010). Los puertos públicos y privados de la región exportan la mayor parte de la producción nacional de cereales y oleaginosas, especialmente soja, en un contexto en el cual ese sector de la economía obtuvo gran rentabilidad, producto de un tipo de cambio favorable y altos precios internacionales (GAÑÁN, 2017).

${ }^{3}$ Resulta necesario realizar una distinción en relación a los términos narco y narcotráfico. Por un lado, narco es una categoría nativa utilizada para mencionar a quienes participan en una determinada posición en este mercado, cuestión que se desarrolla en el presente artículo. En este caso, al igual que con el resto de los términos nativos, se utiliza la cursiva. Por otro lado, narco o narcotráfico en su uso cotidiano por diversos actores sociales (periodistas, expertos, policías, funcionarios, jueces, fiscales) son categorías que incluyen acciones, transacciones, prácticas y actores muy diversos y dispares; suelen estar asociadas y/o utilizarse como auto-explicativas de diversos fenómenos. En este segundo caso, no se emplea la cursiva.

${ }^{4}$ Según la Dirección Nacional de Gestión de la Información Criminal (COZZI, 2018), la ciudad de Rosario mantenía en la última década una tasa de aproximadamente 9 cada 100.000, relativamente baja en relación a la media nacional, de 6.6 cada 100.000. Sin embargo, según datos de Secretaría de Política Criminal y Derechos Humanos del Ministerio Público de la Acusación de la provincia de Santa Fe (Ídem), a partir del año 2012 dicha tasa evidenció un aumento significativo, duplicando en muy poco tiempo su tasa histórica y llegando a su récord en el año 2013, con una tasa de 23 cada 100.000, tendencia que se sostuvo hasta el año 2014, año en que comienza a descender levemente, pero manteniéndose muy por encima de su tasa histórica.

${ }^{5}$ Se prefiere el término ilegalizadas a ilegales porque se pretende dar cuenta de los procesos sociales complejos que las vuelven ilegales. Es decir, que producen la prohibición penal de la producción, tráfico, comercialización y/o consumo de determinadas sustancias. Como, a su vez, los procesos sociales de definición surgen de la iniciativa de determinados actores o grupos, "emprendedores morales" (BECKER, 2009).

${ }^{6}$ Hasta la década del ochenta, los niveles de consumo en la región y en Argentina, eran relativamente bajos (BERGMAN, 2016). Diversos trabajos señalan un aumento sostenido del consumo de drogas ilegalizadas con posterioridad. Varios autores (TOUZÉ, 2008; CALABRESE, 2010; CORBELLE, 2010) indican que desde finales de los años ochenta y noventa en Argentina aumenta de manera progresiva el consumo de cocaína y, en menor medida, opiáceos por vía inyectable. Luego a partir del año 2000 surge una creciente diferenciación entre dos perfiles de usuarios: sectores populares con sustancias de baja calidad (solventes, pegamentos, cocaína, pasta base) y sectores medios altos con sustancias de mejor calidad (cocaína, drogas de diseño y cannabis).

${ }^{7}$ Para muchos lo sigue siendo, ya que el mercado interno es chico en comparación con los llamados países de consumo y también porque los niveles de producción resultan ínfimos en relación a los países productores.

${ }^{8}$ Bajo esta denominación se obscurecen y ocultan una multiplicidad de procesos y prácticas que conducen a la producción de clorhidrato de cocaína, así como consideraciones de orden geopolíticas. En este sentido, un reciente estudio precisa que la mayoría de los centros de elaboración, conocidos popularmente como cocinas, que se relacionan con el procesamiento de derivados de la hoja de coca, no realiza actividades de fabricación -nombre que se le asigna a las fases posteriores a la primera separación de la hoja de coca hasta llegar al clorhidrato de cocaína - propiamente dicha; sino que un número importante de ellos realiza actividades de adulteración - etapa en la que se mezcla el clorhidrato con sustancias de corte (xilocaína, cafeína, manitol) - y fraccionamiento (CORDA, 2014).

${ }^{9}$ Se analiza el tramo temporal que va desde mediados de los años noventa hasta la actualidad, a través de experiencias de tres generaciones de jóvenes. Es decir: quienes son actualmente jóvenes y aquellos que se remiten en sus relatos a las formas en que experimentaron su condición juvenil, en relación a la participación en esas actividades en los años anteriores.

${ }^{10}$ Es importante realizar una distinción nada sencilla, si bien se trabajó con experiencias de sujetos y teniendo en cuenta que cuando se trabaja con experiencias no se focaliza en la historia individual, sino más bien en cómo esa historia representa procesos que pueden ser vistos como patrones que exceden a los individuos. En gran medida lo que ellos relatan da cuenta de posiciones, roles, tareas que muestran transformaciones en las dinámicas de este mercado. Es decir, sus experiencias, más bien, nos informan sobre los cambios en dichos mercados.

${ }^{11}$ Los relatos sobre la propia experiencia no pueden ser analizados como una representación directa de la misma (SIRIMARCO, 2009; PIÑA, 1986), sino más bien como una construcción en la cual se seleccionan elementos o detalles y se descartan otros, se realiza en un momento determinado y en interacción o interlocución con otros (KESSLER, 2013) y está 
moldeada y mediada por un contexto social e institucional. En consecuencia, las respuestas a las mismas preguntas y las reflexiones sobre la propia vida pueden variar según las circunstancias, el interlocutor y a lo largo del tiempo (Ídem).

${ }^{12}$ Proyecto de cooperación internacional, denominado "Intervención multiagencial para el abordaje del delito en el ámbito local", desarrollado por la entonces Secretaría de Seguridad Interior de la Nación, en el marco del Programa de Naciones Unidas para el Desarrollo (PNUD-SSI), 2008/2010, en la que participé como consultora local (FONT, ALES y SCHILLAGI, 2008). "Programa de Inclusión Sociocultural con jóvenes para la prevención del delito y reducción de la violencia", implementado por el estado provincial, 2009/2011, en el que participé como funcionaria de la Secretaria de Seguridad Comunitaria, del Ministerio de Seguridad (FONT, BROGLIA y COZZI, 2011).

${ }^{13}$ Los apellidos, nombres y apodos de las personas, grupos y del barrio que se mencionan han sido modificados para garantizar confidencialidad y anonimato.

${ }^{14}$ Los jóvenes varones suelen reunirse en terrenos baldíos cercanos para jugar al fútbol, especialmente los fines de semana.

${ }^{15}$ Su padre trabajó en uno de los frigoríficos más grandes de la zona y en el puerto de Rosario.

${ }^{16}$ Trabajos esporádicos y temporales, especialmente tareas de albañilería, en un contexto de aumento significativo tanto de la pobreza como de las tasas de desempleo, llegando para el año 2002 al 39 \% (CRUCELLA y ROBIN, 2014) y deterioro notable de las condiciones de los puestos de trabajo (ROBIN y DURAN, 2006), como consecuencia de las políticas económicas implementadas en ese período. Tal como señala Kessler (2013), en Argentina en los noventa se produce una profunda transformación del mundo del trabajo argentino, al igual que otros países de la región, siendo la situación más frecuente la inestabilidad laboral.

${ }^{17}$ El acceso a la cocaína y la marihuana era muy restringido a principios de los ochenta. "El que tomaba merca [cocaína] era millonario, no cualquiera tomaba merca [cocaína], no cualquiera andaba con faso [marihuana], algunos pibes andaban con faso [marihuana], no se vendía, conseguían un pedazo y lo cuidaban. No había droga como ahora, no había tanta droga" (El Gringo).

18 "Mandar a otros a hacer algo" es distinto entonces a "tener el mando": lo primero puede interpretarse como cobardía. En cambio, lo segundo es muestra de autoridad.

${ }^{19}$ Tanto kiosco como búnker son categorías que refieren a modos o formas de comercialización diferentes, sobre esto se vuelve en el próximo apartado.

${ }^{20}$ Si bien este tipo de prácticas también sucedían en momentos previos, aquí aparecieron de manera mucho más extendida.

${ }^{21}$ La diferenciación entre ladrones de caño [armas de fuego] y rastreros está ligada a una cierta profesionalización de los primeros, en relación con los segundos. Quienes son caracterizados como personas que no respetan reglas y suelen robar en el propio barrio.

${ }^{22}$ Diversos estudios de la región han señalado la jerarquización y división de tareas al interior de este mercado (DAY, 2014; ZAMUDIO-ANGLES, 2013; BOURGOIS, 2003; MALVASI, 2012). Cuestiones han sido trabajadas en Cozzi (2018). Así por ejemplo, Zaitch (2013) distingue entre empresarios (jefes, personas que invierten capital, obtienen ganancias y corren riesgos financieros) y empleados (en distintas modalidades de subcontratación que cumplen órdenes sin invertir capital, ni participar en las ganancias).

${ }^{23}$ Los soldaditos también son mencionados como las piernas de los capos. Similar nominación recogió Garriga Zucal (2010) en relación a las jerarquías al interior de una hinchada de fútbol.

${ }^{24}$ En esta clasificación El Gringo Arrieta se desempeñó como narco cuando estuvo ligado a este mercado, y en sus inicios el Abel Montero fue transero del Gringo.

${ }^{25}$ Diversos estudios han señalado el desempeño policial diferencial sobre actividades, grupos y sujetos sociales específicos (PITA, 2012; MISSE, 2007; TELLES, 2012; HIRATA, 2014; FELTRAN, 2011; BARBOSA, 1998).

26 "Ser delincuente" hace referencia sólo a robos o hurtos y no a otro tipo de delitos, de algún modo, sólo los ladrones son delincuentes.

${ }^{27}$ No obstante, la policía no puede pensarse como un actor monolítico, sino más bien existen tensiones, distintos niveles de poder y jerarquías profundamente marcadas al interior de dicha institución; en consecuencia, no todos los policías están en las mismas condiciones para negociar con grupos y personas.

28 "La producción de mercancías políticas generalmente es criminalizada en diferentes códigos penales; pero, al mismo tiempo, es reconocida la tolerancia, mayor o menor, que permite la amplia circulación de mercancías ilícitas, entre ellas las mercancías políticas, lo que define un área de ilegalismos cuya sanción punitiva tiende a transformarse en mercancías políticas" (MISSE, 2017, p. 43). Así podemos interpretar la protección que gozan quienes arreglan con la policía. 


\section{Referencias}

AGUIRRE, Osvaldo. Historias de la mafia en la Argentina. Buenos Aires: Norma, 2010.

BARBOSA, Antônio. Um abraço para todos os amigos: Algumas considerações sobre o tráfico de drogas no Rio de Janeiro. Niteroi: Eduff, 1998.

BECKER, Howard. Outsiders: Hacia una sociología de la desviación. Buenos Aires: Siglo XXI, 2009.

BENASSI, Evangelina. Plantate y boxeá: Jóvenes de sectores populares, circuitos y trabajo. Rosário: Universidad Nacional de Rosario, 2017.

BERGMAN, Marcelo. Drogas, narcotráfico y poder en América Latina. Buenos Aires: Fondo de Cultura Económica, 2016.

BOURGOIS, Philipe. En busca del respeto: Vendiendo crack en Harlem. Buenos Aires: Siglo XXI, 2003.

CALABRESE, Alberto. Prevención del consumo problemático de drogas desde el lugar del adulto en la comunidad educativa. Buenos Aires: Ministerio de Educación de la Nación, 2010.

CLAUS, Waldemar; GONZALEZ, Gustavo; SPEKULJAK, Pablo. "Frontera, rutas y mercados ilegales: Hacia la reconstrucción de los flujos trasnacionales de sustancias ilegales en Argentina (2000-2014)”. Revista Delito y Sociedad, vol. 43, pp. 9-50, 2017.

CORBELLE, Florencia. La construcción del consumidor de drogas en el proceso judicial. Buenos Aires: Universidad de Buenos Aires, 2010.

CORDA, Alejandro; GALANTE, Araceli; ROSSI, Diana. Informe sobre "cocaínas fumables" en Argentina. Buenos Aires: Inédito, 2014.

COZZI, Eugenia. “'Se les dobló el caño, perdieron el honor’: Prácticas, representaciones y valoraciones en relación con la participación de jóvenes en robos y en el mercado de drogas ilegalizadas en un barrio popular de la ciudad de Rosario". Revista Cuestiones Criminales, vol. 1, n. 1, pp. 4-22, 2018.

CRUCELLA, Carlos; ROBIN, Silvia. Sociedad, economía y política en la región del Gran Rosario (2003-2011). Rosário: Ediciones DelRevés, 2014.

DAY, Marcus. "Haciendo una montaña de un grano de arena: mitos sobre jóvenes y delincuencia en Santa Lucía”. Transnational Institute: Serie Mercados de Drogas y Violencia, n. 3, 2014. Disponível em: https://www.tni.org/es/publicacion/haciendo-una-montana-de-un-grano-dearena-mitos-sobre-jovenes-y-delincuencia-en-santa

EPELE, María. "Etnografía, fragmentación social y drogas: Hacia una política de las miradas". Etnografías Contemporáneas, n. 3, pp. 117-142, 2007.

EPELE, María. Sujetar por la herida: Una etnografía sobre drogas, pobreza y salud. Buenos Aires: Paidós, 2010.

EPELE, María. Padecer, cuidar y tratar: Estudios socio antropológicos sobre consumo problemático de drogas. Buenos Aires: Antropofagia, 2012. 
FELTRAN, Gabriel. Fronteiras de tensão: Política e violência em grupos populares. Porto Alegre: Editora da UFRGS, 2011.

FONSECA, Claudia. "La clase social y su recusación etnográfica”. Etnografías Contemporáneas, año 1, pp. 117-138, 2005.

FONT, Enrique; ALES, Cecilia; SCHILLAGI, Carolina. "Intervención multiagencial para el abordaje del delito en el ámbito local”. Cuadernos de Seguridad, n. 7-8, pp. 193-219, 2008.

FONT, Enrique; BROGLIA, Francisco; COZZI, Eugenia. “Avances en las intervenciones de inclusión sociocultural con jóvenes como mecanismos de prevención del delito y reducción de la violencia en dos ciudades de la provincia de Santa Fe". IV Seminario Internacional Políticas de la Memoria: Ampliación del campo de los derechos humanos. Memoria y perspectivas, Buenos Aires, 2011.

GAÑÁN, Javier. Entre la negación y la adaptación: La política pública del Ministerio de Seguridad de la Provincia de Santa Fe en relación al "narcomenudeo" a partir del caso Los Monos. Rosario, 2012-2015. Monografia (Licenciatura em Ciência Política y Relações Internacionais) - Universidad Nacional de Rosario, Rosário, 2017.

GARRIGA ZUCAL, José. Nosotros nos peleamos: Violencia e identidad de una hinchada de fútbol. Buenos Aires: Prometeo Libros, 2010.

HIRATA, Daniel. "O ponto e a biqueira: Notas para a construção de um conceito". In: BARREIRA, César et al. (orgs). Violência, ilegalismos e lugares morais. Campinas: Pontes Editores, 2014, pp. 311-324.

HIRATA, Daniel; GRILLO, Carolina. "Sintonia e amizade entre patrões e donos de morro: Perspectivas comparativas entre o comércio vajerista de drogas em São Paulo e no Rio de Janeiro". Tempo Social: Revista de Sociologia da USP, vol. 29, n. 2, pp. 75-98, 2017.

INDEC. Censo nacional de población, hogares y viviendas 2010: Censo del bicentenario. Resultados definitivos, serie B, n. 2. Buenos Aires: Instituto Nacional de Estadística y Censos, 2012.

KESSLER, Gabriel. "Ilegalismos en tres tiempos”. In. CASTEL, Robert et al. (orgs). Individuación, precariedad, inseguridad: ¿Desinstitucionalización del presente? Buenos Aires: Paidós, 2013, pp. 109-161.

KESSLER, Gabriel. Controversias sobre la desigualdad: Argentina 2003/2013. Buenos Aires: Fondo de Cultura Económica, 2014.

MALVASI, Paulo. Interfaces da vida loka: Um estudo sobre jovens, tráfico de drogas e violência em São Paulo. São Paulo: Edusp, 2012.

MISSE, Michel. "Mercados ilegais, redes de proteção e organização local do crime no Rio de Janeiro". Estudos Avancados, vol. 21, pp. 139-157, 2007.

MISSE, Michel. Mercancías políticas. In: BRÍGIDA, Renoldi; SANTIAGO, Álvarez; SALVADOR, Maldonado Aranda (orgs). Estado, violencia y mercado: Conexiones etnográficas en América Latina. Buenos Aires: Antropofagia, 2017, pp. 39-46.

PIÑA, Carlos. "Sobre las historias de vida y su campo de validez en las ciencias sociales”. Revista Paraguaya de Sociología, n. 67, pp. 143-162, 1986.

PITA, María. "Poder de policía y administración de grupos sociales: Vendedores ambulantes senegaleses en la Ciudad Autónoma de Buenos Aires”. In: AZAÏS, Christian; KESSLER, Gabriel; TELLES, Vera da Silva (orgs). Ilegalismos, cidade e política. Belo Horizonte: Fino Traço, 2012, pp. 109-140. 
RANGUGNI, Victoria. El paco bajo la lupa, el mercado de la pasta base de cocaína en el Cono Sur. Buenos Aires: Transnational Institute, 2006.

ROBIN, Silvia; DURAN, Paula. "La evolución reciente de la pobreza por ingresos en el gran Rosario y su impacto sobre los jóvenes”. Revista Acceso Directo, n. 1, pp. 117-136, 2006.

RUBINZAL, Diego. Historia económica argentina. 1880-2009: Desde los tiempos de Roca hasta Kirchner. Buenos Aires: Centro Cultural de la Cooperación, 2010.

SAÍN, Marcelo. La regulación del narcotráfico en la provincia de Buenos Aires. Buenos Aires: Universidad Metropolitana para la Educación y el Trabajo, 2015.

SIRIMARCO, Mariana. De civil a policía: Una etnografía del proceso de incorporación a la institución policial. Buenos Aires: Teseo, 2009.

TELLES, Vera. "Jogos de poder nas dobras do legal e ilegal: Anotações de um percurso de pesquisa”. In: AZAIIS, Christian; KESSLER, Gabriel; TELLES, Vera da Silva (orgs). Ilegalismos, cidade e política. Belo Horizonte: Fino Traço, 2012, pp. 27-56.

TOKATLIAN, Juan. ¿Qué hacer con las drogas? Una mirada progresista sobre un tema habitualmente abordado desde el oportunismo político y los intereses creados. Buenos Aires: Siglo XXI, 2017.

TOUZÉ, Graciela. Saberes y prácticas sobre drogas: El caso de la pasta base de cocaína. Buenos Aires: Intercambios Asociación Civil, 2008.

ZAITCH, Damián. "Reducción de daños, seguridad y tráfico de drogas ilícitas". Cuadernos de Seguridad, n. 2, pp. 51-82, 2008.

ZAMUDIO-ANGLES, Carlos Alberto. "Jóvenes en el narcomenudeo: El caso Ciudad de México". Revista Latinoamericana de Seguridad Ciudadana, n. 13, junio, pp. 111-123, 2013.

RESUMEN: El artículo analiza algunas transformaciones en el mercado de drogas ilegalizadas - marihuana y cocaína - sucedidas en las dos últimas décadas, en un barrio popular de la ciudad de Rosario, Argentina. A partir de reconstruir, desde una perspectiva etnográfica, trayectorias de jóvenes pertenecientes a tres generaciones, se pretende dar cuenta de cambios más generales. Las transformaciones serán presentadas y organizadas en tres dimensiones: las formas de organización y distribución interna de tareas y la configuración de variados puestos y roles; la forma de venta al por menor; y finalmente, las formas de vincularse con la policía.

Palavras-chave: mercado, drogas, delito, jóvenes, policía
EUGENIA COZZI (eugecozzi@gmail.com) é pósdoutoranda do Conselho Nacional de Pesquisa Científica e Técnica (Conicet, Buenos Aires, Argentina), professora de criminologia na Faculdade de Direito da Universidad Nacional de Rosario (UNR, Santa Fe, Argentina) e pesquisadora da Equipe de Antropologia Política e Jurídica (EAPJ) da Faculdade de Filosofia e Letras da Universidad de Buenos Aires (UBA, Buenos Aires, Argentina). Tem doutorado em antropologia pela UBA, mestrado em criminologia pela Universidad Nacional del Litoral (UNL, Santa Fe, Argentina) e graduada em direito pela UNR.

https://orcid.org/0000-0002-9108-5905 